\title{
Back to the fields: COVID-19 impact on agricultural activity detected with satellite data
}

\author{
A. T. Hammad ${ }^{a, b, *}$ G. Falchetta ${ }^{b, c, d}$, I. B. M. Wirawan ${ }^{b}$ \\ a Università Cattolica del Sacro Cuore, Milan, Italy \\ b Decatab Pte Ltd., Singapore \\ c Free University of Bozen-Bolzano, Italy \\ d Future Energy Program, Fondazione Eni Enrico Mattei, Milan, Italy \\ * Corresponding author. Email address: ahmed@decatab.com
}

This manuscript has been submitted for publication in Environmental Research Communications. It has not been peer-reviewed. Subsequent versions of this manuscript may have slightly different content. If accepted, the final version will be available via the "Peer-reviewed Publication DOI" link on the Earth ArXiv webpage. Please feel free to contact the authors with any feedback. 


\title{
Back to the fields: COVID-19 impact on agricultural activity detected with satellite data
}

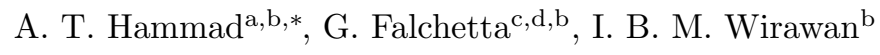 \\ ${ }^{a}$ Università Cattolica del Sacro Cuore, Milan, Italy \\ ${ }^{b}$ Decatab Pte Ltd., Singapore \\ ${ }^{c}$ Free University of Bozen-Bolzano, Italy \\ ${ }^{d}$ Future Energy Program, Fondazione Eni Enrico Mattei, Milan, Italy
}

\begin{abstract}
In response to the COVID-19 pandemic, policymakers worldwide adopted unprecedented measures to limit disease spread, with major repercussions on labour markets and economic growth. Here we provide empirical evidence of their impact on agricultural activity due to sectoral labour reallocation in tourist-dependent regions, a widely covered phenomenon by the international press. Analysing daily satellite data in a nonparametric machine learning statistical framework over cropland in Badung, a highly populated regency of Bali, Indonesia, we generate a counterfactual synthetic EVI based on gradient boosted decision trees trained on a set of environmental variables assuming no lockdown occurrence. Based on the counterfactual, we estimate a significant increase in the EVI vegetation index over cropland after the beginning of a lockdown period. The finding is robust to a placebo test. We then exploit the heterogeneity of the region analysed, where the South is dominated by tourism and the tertiary sector and the North is already mostly agricultural, and we find a stronger effect in the former. This results suggests that the observed increase in remotely sensed vegetation indexes is likely driven by a labour force reallocation towards the primary sector to compensate for the income lost from previous employment. Overall, our results show that statistical analysis of satellite data can be an effective methodology to observe the impact of a labour force crowding into the agricultural sector in response to an exogenous shock in other labour sectors.

Keywords: agricultural productivity, remote sensing, non-parametric econometrics, COVID-19, labour market shift, Indonesia
\end{abstract}




\section{Introduction}

Tourism-dependent economies - where a large share of the local gross domestic product and of the workforce is employed in the touristic sector - have been among the worst hit by the restrictions imposed during the COVID-19 pandemic. Bali, with a population of 4.4 million, is Indonesia's tourism engine and more than half of its economy depends directly on tourism.

Bali is also an important agriculture hotspot (see Figure Appendix A.1). $72 \%$ of the land is used for agricultural activities and the agricultural sector is the second largest contributor to Bali's income in 2020 (BPS, 2020). Aside from rice, the main cultivated crop, farmers cultivate several horticulture commodities such as chayote, cabbage, and chilli (BPS, 2018).

Since COVID-19 outbreak in Bali, Indonesia, the tourism sector has been heavily affected by the restriction measures that the Indonesian government has taken following the rest of the world (BPS, 2020). In April, Indonesia banned all foreign tourists (Minister of Law and Human Rights, 2020). Nonetheless, the number of cases has kept increasing and as per the 27th of November 2020, there have been 13,730 cases reported according to the Bali Provincial Health Office (Kesehatan, 2020).Travel restrictions, limited social activities, and interactions caused a dramatic drop down in the number of tourists around the island (Laula and Paddock, 2020). The number of foreign tourists decreased by roughly $31 \%$ as compared with January 2019 and by $16 \%$ as compared with the same month one year before (Udayana, 2020).

To cope with the dramatic condition of the tourism industry, formerly the first source of income (Antara and Sumarniasih, 2017), the Balinese labour force reallocated towards the primary sector, making agriculture-related activities central in their daily lives as a financial lifeline. These dynamics have been widely reported by the international press, such as the New York Times (Laula and Paddock, 2020) and the Deutsche Welle (Welle, 2020), as well as local universities (Udayana, 2020). The process also coincided with a quick deurbanization.

Irrespective of the anecdotal and journalistic evidence, there has been no empirical

${ }^{*}$ Corresponding author. E-mail address: ahmed@decatab.com. DECATAB PTE. LTD. 20 COLLYER QUAY \#09-01 SINGAPORE (049319) 
assessment of this sectoral labour reallocation. In addition, there has been no official statistics release as the vast majority of the agricultural employment is either informal or family-run.

To empirically evaluate this shift, here we provide evidence of the impact of the lockdown on agricultural activity on Badung regency by comparing a time series of Moderate Resolution Imaging Spectroradiometer (MODIS) measured Enhanced Vegetation Index (EVI) and a counterfactual synthetic EVI based on gradient boosted decision trees trained on a set of environmental variables assuming no lockdown occurrence.

The key novelty of our analysis lies in the detection and statistical assessment of a labour market reallocation caused by an exogenous shock (the COVID-19 pandemic) through the use of satellite data. The paper contributes to the multidisciplinary literature linking the use of remotely sensed environmental data with machine learning algorithms and the econometric approaches to impact evaluation of policy.

\section{Background}

\subsection{The impact of COVID-19 on labour markets}

The COVID-19 pandemic is exerting enormous pressure on the global economy in both higher and lower income countries. The observed labour market responses have however been remarkably different (Bartik et al., 2020): in high income countries a significant share of the population is employed in the tertiary sector and could therefore move to home working without significant changes in the work productivity. Workers of more affected sectors could receive compensation and income support schemes from national governments, which overall mitigated the short-run household income plunge.

Conversely, in middle and lower income countries many people's incomes largely depend on agriculture, handcraft or tourism (Danquah et al., 2020). The latter was one of the most affected sectors: according to recent estimates (WTTC, 2020), up to 75 million tourism sector workers are at immediate job risk as a result of COVID-19, with a travel tourism GDP loss in 2020 of up to $\$ 2.1$ trillion. Yet, lower income countries' governments often lack the means to support workers who lost their jobs as a consequence of COVID-19 limitations on social interactions. In these regions, populations were thus hit more harshly by the pandemic, and faced the necessity to adopt autonomous adaptation 
actions to try to compensate for the reduction or lack of their previous income (Ataguba, 2020). Reports have shown that many tourist workers have decided to go back to their towns of origin to pursue agricultural activities and mitigate the labour demand shock in their previous employment sectors (Laula and Paddock, 2020; Welle, 2020).

\subsection{Estimating agricultural productivity with satellite data}

The literature on the assessment of agricultural systems and productivity through the use of satellite data has proven the role that satellite imagery can play at a variety of scales (Jia et al., 2019) and the depth of the insights that they can provide. This is especially true for developing countries (Lobell et al., 2018), such as Indonesia (Yamamoto et al., 2019). For instance, a large body of literature has shown that composite indexes based on multi-spectral satellite observations - such as the NDVI and EVI indexes - can be effective proxies to detect and forecast yield variation of a multitude of crops such as soybeans, rice, and wheat, even in smallholder agriculture, with results consistent with official yield statistics and correlation maps of historical yield data. Vegetation indexes are also well suited to study scattered agricultural topography and to inform management decisions on the optimal timing for planting and harvesting.

A recent review by Jia et al. (2019) points out how advances in machine learning and the availability of data from earth observing satellites can dramatically improve the ability to map croplands over long periods and over large regions. This includes the capacity to link vegetation productivity to remotely sensed estimates of absorbed photosynthetically active radiation.

Lobell et al. (2018) use data from a survey experiment in Uganda to evaluate the accuracy of Sentinel-2 remotely-sensed plot-level maize yields with respect to groundbased measures relying on farmer self-reporting. Similarly, Wolanin et al. (2019) apply machine learning to a process-based model to estimate crop primary productivity from Sentinel-2 and Landsat 8 satellite data. They highlight the benefit of using the red edge bands from Sentinel-2 in increasing estimation accuracy. Cai et al. (2019) integrate satellite and climate data to predict wheat yield in Australia using machine learning approaches. They highlight a generally very high estimation accuracy, with optimal prediction performance can be achieved two-month lead time before harvest. Burke and Lobell (2017) demonstrate the potential to track smallholder maize yield variation 
in western Kenya using a combination of 1-m Terra Bella imagery and intensive field sampling on thousands of fields over 2 years. They obtain $\mathrm{R}^{2}$ coefficients of up to 0.4 . Their method can also detect positive yield responses to fertilizer and hybrid seed inputs.

Kubitza et al. (2020) review literature on the use of satellite data to assess adoption and impacts of agricultural management practices in developing countries. They find that in general satellite data are successful in detecting cropping intensity, tillage, crop residue cover, irrigation, and soil and water conservation. They highlight that only a limited number of studies has engaged with estimating yield impacts and the economic implications, irrespective of solid methodologies having been developed. Sjöström et al. (2011) appraised the potential of MODIS EVI for modeling gross primary production across African Savannah ecosystems. In their study, EVI was found to correlate well with estimated GPP on a site-by-site basis.

Son et al. (2014) carry out a comparative analysis of multitemporal MODIS EVI and NDVI indexes data for large-scale rice yield estimation in the Mekong River Delta. They find that the approach could be used to estimate rice production prior the harvesting period through the use of physical crop yield models, and that EVI-based models were more accurate than those from NDVI-based models. Their correlation coefficients $\left(\mathrm{R}^{2}\right)$ range from 0.62 to 0.71 for spring-winter and 0.4 to 0.56 for summer-autumn rice crops, respectively. Figueiredo et al. (2016) estimated correlation maps to assess historical yield during the soybean crop cycle from EVI data in Paraná State, Brazil. Their model was able to explain $96 \%$ to $98 \%$ of the variance in estimated yield from correlation maps.

Duveiller et al. (2012) demonstrated how it is possible to monitor the growth and evolution of winter wheat over a decade using the green area index (GAI) even on a highly fragmented topography characterized by non-wheat areas within the spatial resolution of MODIS. Their results are congruent with ground trough data at both the regional and the filed level with a relative root mean square error (RRMSE) of $25.7 \%$ and $37.6 \%$, respectively.

(Jain et al., 2017) developed a 30-meter resolution yield maps to explore the causes of yield gaps of smallholders in the Indo-Gangetic Plains, India. Using a crop model simulation, the authors were able to rely only on satellite vegetation indices without the need for any ground data. Finally using Random forest the authors proved that roughly 
$80 \%$ of the variance in yields is explained by differences in the weather conditions and management practices (such as the saw timing)Their results suggest that yield could be increased by 11 to $32 \%$ if more focus is given to the later.

\subsection{Study area}

Badung is one of the 9 regencies in the island of Bali, Indonesia. It spans over $418.52 \mathrm{~km}^{2}$ (Figure 1) from north to south and consists of 6 districts and 46 villages (Table 1. Like the rest of the island, Badung Regency relies on tourism as its main source of income but according to Central Bureau of Statistics (BPS, 2020), it is also the richest regency (the revenues in 2019 Badung were higher than the total revenues from other 8 regencies in Bali), the one with the highest minimum wage (IDR 2,9 million), the lowest percentage of people in poverty $(1.78 \%)$ and the one that has experienced the highest annual population growth rate from 2010-2019 (2.36\%). Based on recent statistics, around 140,000 people in Badung regency work in the tourism sector, and only 3,000 work in agricultural-related activities (BPS, 2020).

According to the Central Bureau of Statistics (BPS, 2020), its two biggest districts are Petang and Kuta Selatan. The southern districts (Kuta, Kuta Selatan, Kuta Utara) are characterised by a strong tertiary sector that has been constantly growing together with the population living in the three districts. On the other hand, the northern districts (Mengwi, Abiansemal, Petang) are mostly agricultural areas where the population has remained overall steady in the last few years and tourism has grown slowly as compared with the south. The population of Kuta Selatan, the center of tourism activities of the island, grew by $4.4 \%$ in 2018-2019, while the population of Petang, the center of agricultural activities declined by $-0.22 \%$ in the same period. 


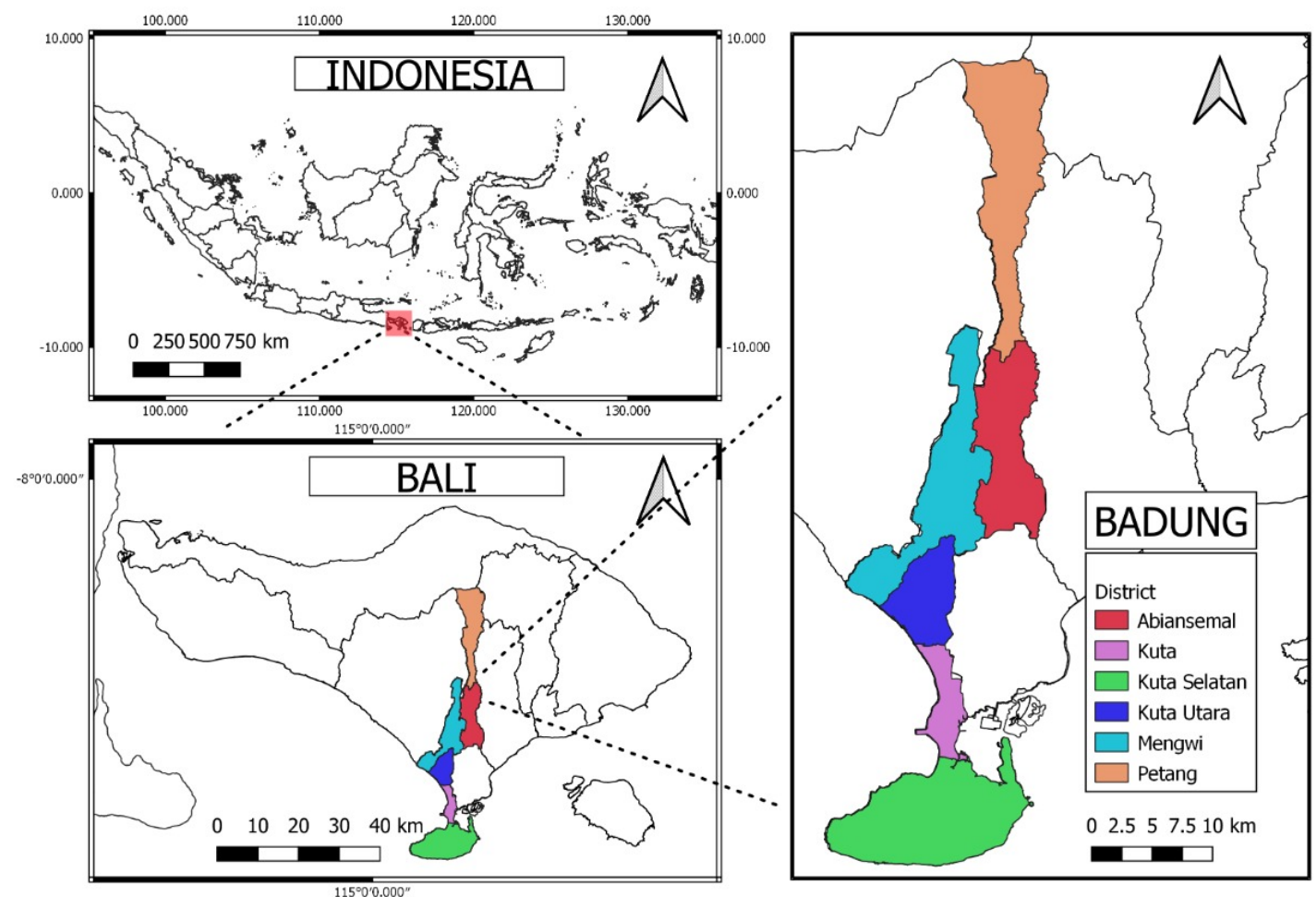

Figure 1: Map of the Badung Regency and its geographical position

Table 1: Districts of Badung

\begin{tabular}{cccc}
\hline District & Area $\left(\mathrm{km}^{2}\right)$ & Percentage of Area & Avg. distance to Denpasar $(\mathrm{km})$ \\
\hline Kuta Selatan & 101,13 & 24.16 & 18.3 \\
Kuta & 17,52 & 4,19 & 9,5 \\
Kuta Utara & 33,86 & 8,09 & 6,6 \\
Mengwi & 82,00 & 19,59 & 15 \\
Abiansemal & 69,01 & 16,49 & 15 \\
Petang & 115,00 & 27,48 & 30 \\
\hline Source: Central Bureau of Statistics Indonesia Badung Regency (2020)
\end{tabular}

Badung, and in particular its northern districts, is also an important agriculture hot spot: $45 \%\left(190.49 \mathrm{~km}^{2}\right)$ of its territory $\left(418.52 \mathrm{~km}^{2}\right)$ is devoted to agricultural activities (see Figure Appendix A.1). Most rice fields are located in the southern area 
of Badung (which has lower altitude). In contrast, non-paddy commodities are located in the northern area of the regency, where the most important horticulture commodities are coconut (201,840 ha), rice (12,943.13 ha), chayote (152 ha) and chilli (105 ha) (BPS, 2020).

A tropical climate characterises Badung and more in general Bali, with monsoon from October to April (wet season). According to data from Meteorogical, Climatological, and Geophysical Office - Region III Denpasar (BPS, 2020), January is the period with the most abundant precipitations (about $340 \mathrm{~mm}$ ) and highest number of rainy days (18 days).

\section{Conceptual framework}

The empirical analysis presented in this paper builds on the following underlying conceptual framework. This is grounded on basic macroeconomic principles of labour demand and supply, factor productivity, and wage.

As a consequence of an exogenous shock (the travel restrictions imposed by the COVID-19 pandemic), individual $i$ faces a reduction in labour demand $L^{d}$ from sector $C$ where (s)he is currently employed:

$$
\Delta L_{C}^{d}<0
$$

In the case under analysis, this is the tourism-related sector. This reduction in turn implies a decrease in wages in the sector $w_{C}$

$$
\Delta w_{C}<0
$$

because labour supply $L^{s}$ is constant over the short run:

$$
\Delta L_{C}^{s}=0
$$

In response, individual $i$ decides to engage in the agricultural sector $A$, where in the short-run labour demand is constant:

$$
\Delta L_{A}^{d}=0
$$


Agricultural productivity $A P$, defined as the quantity of output $Y$ over cultivated area $A$ at time $t$, is a function of labour $L$, capital $K$, and technology $T$ :

$$
A P_{t}=f(L, K, T)=\frac{Y_{t}}{A_{t}}
$$

The increase in labour supply to the agricultural sector determines a short-run increase in the productivity because in general

$$
\frac{\partial A P_{t}}{\partial L}>0
$$

holds, although at a decreasing pace because of the law of decreasing returns to scale:

$$
\frac{\partial^{2} A P_{t}}{\partial L^{2}}
$$

As discussed in Section 2.2, there is significant empirical evidence that a change in $A P_{t}$ can be anticipated and proxied by vegetation indexes such as the EVI (see the relevant literature above and the Materials and Methods section) calculated from satellite data multispectral data.

\section{Materials and methods}

\subsection{Data sources and processing}

The analysis is based on remotely sensed environmental and atmospheric data detailed in Table 2. The data includes the MODIS EVI and the variables used as predictors in the model. A time series is assembled based on data from the beginning of 2010 to 9th of July 2020. Raw data is processed in Google Earth Engine (Gorelick et al., 2017), where each remotely-sensed variable is first masked over cropland pixels (as from the GFSAD1000 gridded cropland product (Teluguntla et al., 2015); then, the mean value of each variable is extracted for each of the 6 districts of Badung for each day of the period considered.

The processed data are imported into the $\mathrm{R}$ scientific programming environment, where the data.table (Dowle et al., 2019), caret (Kuhn et al., 2008), and Xgboost (Chen et al., 2015) packages are used for statistical analysis. 
Before the model training stage, missing data (19\%) are imputed through a chained random forest Stekhoven and Buhlmann (2011) as implemented in the package MissRanger Mayer (2019) where each variable containing missing values are imputed by using all the other variables as predictors iteratively until the mean out-of-bag (OOB) error reach its minimum value. Finally, a Savitzky-Golay filter is applied to remove the noise that characterises satellite data (see Chen et al. (2004)).

Table 2: Input data table

\begin{tabular}{|c|c|c|}
\hline Data product & Variable & Source \\
\hline $\begin{array}{l}\text { GFSAD1000: Cropland Extent } \\
\text { 1km Multi-Study Crop Mask }\end{array}$ & landcover & Teluguntla et al. (2015) \\
\hline MODIS Terra Daily EVI & EVI & Huete et al. (2002) \\
\hline $\begin{array}{l}\text { CHIRPS Daily: Climate Hazards } \\
\text { Group InfraRed Precipitation with } \\
\text { Station Data (version } 2.0 \text { final) }\end{array}$ & precipitation & Funk et al. (2015) \\
\hline $\begin{array}{l}\text { MOD11A1.006 Terra Land } \\
\text { Surface Temperature and } \\
\text { Emissivity Daily Global } 1 \mathrm{~km}\end{array}$ & LST_Day_1km & Wan et al. (2015) \\
\hline $\begin{array}{l}\text { ERA5 Daily aggregates - Latest cli- } \\
\text { mate reanalysis produced by ECMWF } \\
\text { / Copernicus Climate Change Service }\end{array}$ & $\begin{array}{l}\text { u_component_of_wind_10m, } \\
\text { v_component_of_wind_10m }\end{array}$ & Cucchi et al. (2020) \\
\hline $\begin{array}{c}\text { CFSV2: NCEP Climate Forecast } \\
\text { System Version 2, 6-Hourly Products }\end{array}$ & $\begin{array}{l}\text { Maximum specific humidity } 2 \mathrm{~m} \\
\text { above ground, } 6 \text {-hour interval }\end{array}$ & (Saha et al., 2011) \\
\hline $\begin{array}{l}\text { MOD16A2.006: Terra Net Evapo- } \\
\text { transpiration 8-Day Global } 500 \mathrm{~m}\end{array}$ & Total evapotranspiration & Running et al. (2017) \\
\hline Bali shapefile & Administrative boundaries & $\begin{array}{l}\text { Center for the Management and Dis- } \\
\text { semination of Geospatial Information. } \\
\text { Indonesia Geospatial Information } \\
\text { Agency Accessed 2020-11-27 from } \\
\text { https://tanahair.indonesia.go.id/portal- } \\
\text { web/download/perwilayah }\end{array}$ \\
\hline
\end{tabular}

\subsection{Agricultural indexes considered}

The technological advances and the need to account for the specific features of a given study area have brought researchers to develop a multitude of vegetation indexes (Viña et al., 2011). For example, the EVI (Enhanced Vegetation Index, Equation 8) was developed to better account for atmospheric conditions and light reflection from the ground that causes several issues with the traditional NDVI (Normalized Difference Vegetation Index) measurement (Equation 9. 


$$
\begin{gathered}
E V I=2.5 \times N I R-R E D \times(N I R+6 \times R E D-7.5 \times B L U E)+1 \\
N D V I=\frac{(N I R-R E D)}{(N I R+R E D)}
\end{gathered}
$$

where NIR, RED, and BLUE represent the wavelength bands measured by a satellite.

In particular, the EVI includes additional wavelengths and adjustment parameters to correct for the inaccuracies of NDVI (Huete et al., 2002). Variations in solar incidence angle, atmospheric conditions like distortions in the reflected light caused by the particles in the air, and signals from the ground cover below the vegetation are corrected for using EVI. Moreover, the NDVI is mostly chlorophyll sensitive, while the EVI is more responsive to canopy structural variations (Morcillo-Pallarés et al., 2019).

\subsection{Statistical modelling}

\subsubsection{Time-Series Prediction of EVI in a machine learning framework}

In order to estimate the causal effect of the lockdown on agriculture activity, we compare the factual EVI time series of the study area of interest with a simulated EVI time series based on gradient boosted decision trees. In other words, we use historical data to build synthetic counterfactual. The difference between observed values of EVI and the synthetic counterfactual is the effect of the lockdown on agriculture activity.

Using the aforementioned data, we applied the extreme gradient boosted decision trees algorithm (Friedman, 2001) on the first 9 years (from the 1st of January 2010 to 1st April 2019) of data for each of the 6 districts of Badung. To enhance the accuracy of the model and to account for trends and seasonality, we generate several lagged features for each predictor and calculated the average values of temperature and humidity over the previews 15 and 30 days and the precipitation accumulation for the same time period. We also include year, month, day, week of the year, day of the year, and sine and cosine function of time (for week, month, and year) as additional predictors.

We use a 10 fold cross-validation with a random search over 100 parameters to find the best hyperparameters (Wright and Ziegler, 2015) and evaluate the model performance with the root mean square error (RMSE). Finally, the year preceding the lockdown (from the 2nd of April 2019 to the 1st of April 2020) is used as a test set. 


\subsubsection{Lockdown effect on EVI estimation}

After model training and testing to generate the synthetic projection, we estimate the effect of the lockdown as the difference between the synthetically estimated time series and the actual data $\left(\Delta_{\text {Observed,Counterfactual }}\right)$ before and after the lockdown. We then subtract our prediction to the observed value of EVI and we estimate as per Equation 10:

$$
\Delta_{\text {Observed,Counterfactual }}=y_{i t}-\rho_{i t}=\alpha+\beta T_{t}+\epsilon_{i t}
$$

where $y_{i t}$ is EVI measured on district $i$ on day $t, \rho_{i t}$ is the predicted value, and $T$ is a dummy equal to 1 during the lockdown and 0 prior to it. We weight each observation based on the cropland area (measured in square meters) for each district to account for differences in cropland surfaces. An analogous methodology is applied in Granella et al. (2020) to estimate the effect the lockdown on pollution levels.

\subsection{Robustness checks}

To ensure that our results are not driven by a different treatment than the lockdown, we use a placebo test with the treatment period set one year before the actual lockdown (from the 2nd of April 2019 to the 9th July 2019). To carry out the test we: (i) drop all the outcomes for treated observations after they receive treatment (the beginning of the lockdown); (ii) insert a phantom treatment event in the middle of the remaining data (we select one year before the lockdown); (iii) run the linear estimation model and evaluate the significance of the $\beta$ coefficient from Equation 10.

\section{Results}

\subsection{ML model training and testing}

Table 3 presents the R-squared $\left(\mathrm{R}^{2}\right)$, root mean square error (RMSE), and mean absolute error (MAE) for both the training dataset (from the 1st of January 2010 to 1st April 2019) and test dataset (from the 2nd of April 2019 to the 1st April 2020) for the whole study area as an average of the 6 districts. Figure 2 illustrates the average observed and predicted value of EVI for the whole regency of Badung before and after the lockdown. 
Table 3: Model training and testing benchmarks

\begin{tabular}{cccc}
\hline Dataset & $\mathrm{R}^{2}$ & RMSE & MAE \\
\hline Train & 0.9297 & 0.0117 & 0.0093 \\
Test & 0.7382 & 0.0193 & 0.0154 \\
\hline
\end{tabular}

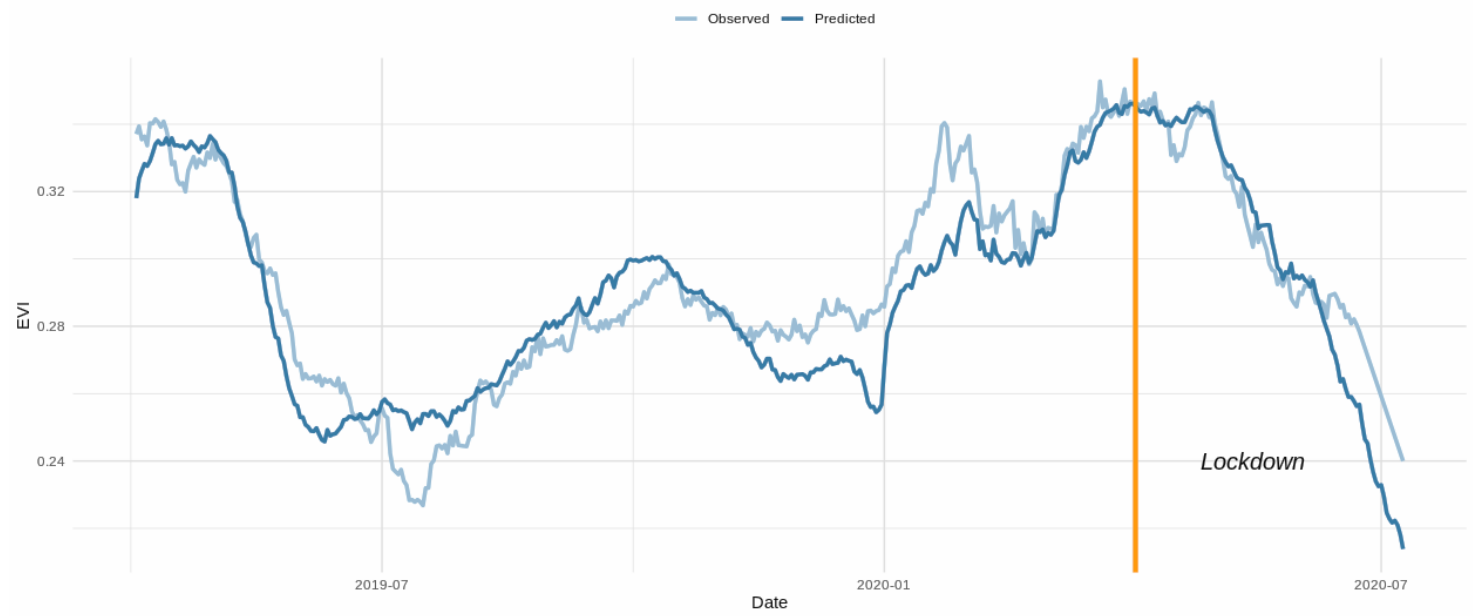

Figure 2: Time series of EVI index (observed and synthetic counterfactual) in Badung

The results show that our model is able to closely learn the historical EVI variation over cropland in Badung based on our set of atmospheric and seasonal predictors, with a training accuracy of $93 \%$. When testing the trained model on unseen data (the future, compared to the training data time span), the model performs relatively well, with a testing accuracy of $74 \%$. 


\subsection{Lockdown impact on agricultural activity}

Table 4: Lockdown impact on $\Delta_{\text {Observed,Counterfactual and heterogeneity }}$ effect on Northern and Southern Districts

\begin{tabular}{llll}
\hline \multirow{2}{*}{ Lockdown } & Badung & \multicolumn{1}{c}{ North } & South \\
\cline { 2 - 4 } & $0.00352^{* * *}$ & $0.00372^{* *}$ & $0.00286^{*}$ \\
& $(0.00095)$ & $(0.00137)$ & $(0.00117)$ \\
Intercept & $0.00347^{* * *}$ & $0.00518^{* * *}$ & $-0.00200 * * *$ \\
& $(0.00044)$ & $(0.00063)$ & $(0.00054)$ \\
\cline { 2 - 4 } $\mathrm{N}$ & 2790 & 1395 & 1395 \\
\hline
\end{tabular}

*** $\mathrm{p}<0.001 ; * * \mathrm{p}<0.01 ; * \mathrm{p}<0.05$.

Table 4 reports the results of the effect estimation model of Equation 10. We find that the lockdown has on average increased the value of EVI on the whole Badung regency by 0.00352 which corresponds to an increase of $1.17 \%$, from the average values that would have been observed had the epidemic not occurred. This result is highly statistical significant.

To explore the heterogeneity effect of the lockdown on the north and southern districts we run separate regression models for the two areas. It must be remarked that in the study area, the South is dominated by tourism and the tertiary sector while the North is mostly agricultural. Figures 3-4 illustrate the average observed and predicted value of EVI for the two geographical areas before and after the lockdown, In the north the EVI has increased by $1.06 \%$ while in the south $1.15 \%$. The coefficient for the north model has higher statistical significance, but both coefficients are significant at a $5 \%$ level. The stronger effect in the south can be justified by a stronger labour force reallocation towards the primary sector to compensate for the income lost from previous employment. 


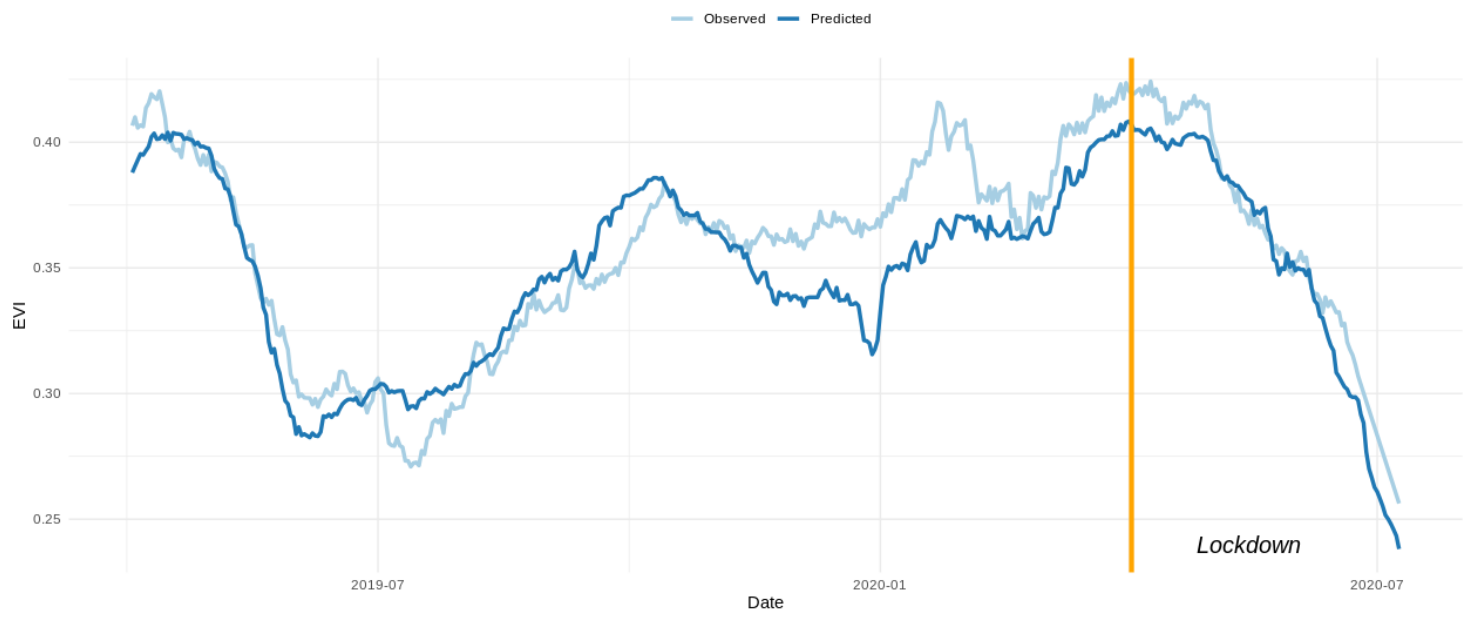

Figure 3: Time series of EVI index (observed and synthetic counterfactual) in North Badung

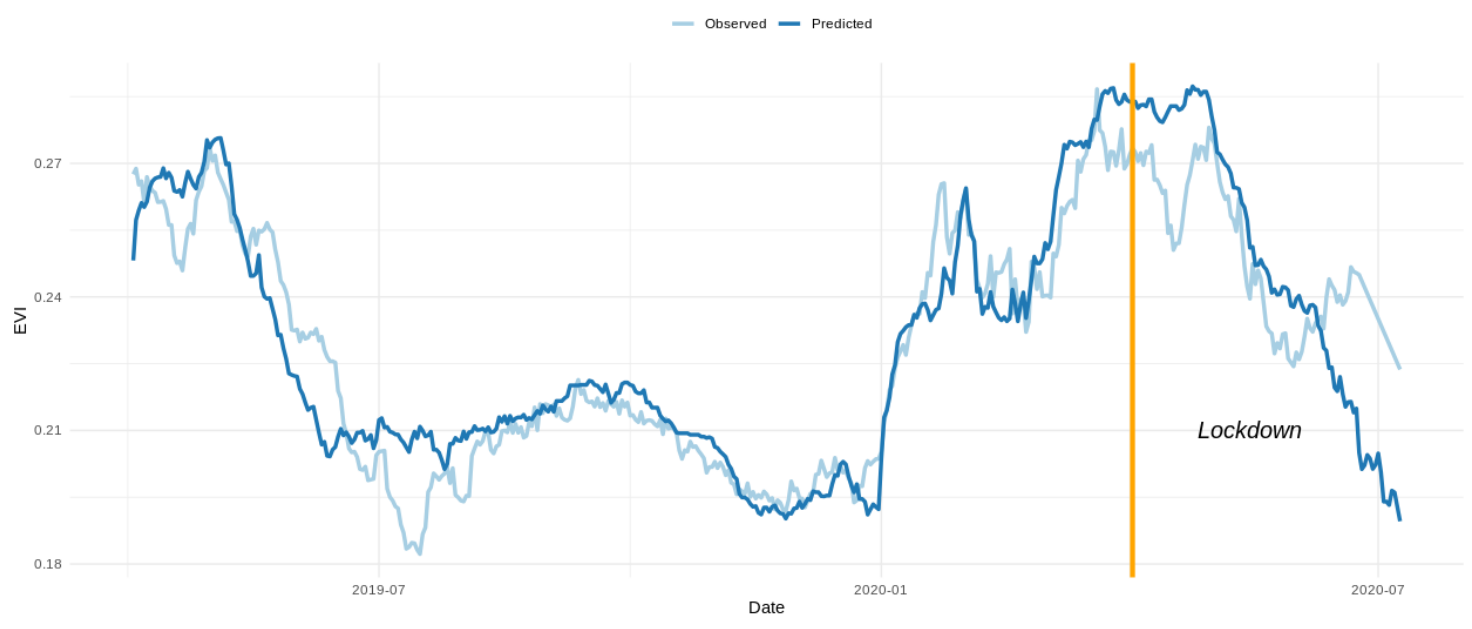

Figure 4: Time series of EVI index (observed and synthetic counterfactual) in South Badung

\subsection{Placebo test}

Table 5 and Figure 5 report the result of the regression model based on Equation 10 used to estimate the lockdown effect alongside the result of the placebo test in which the pseudo treatment is set one year before the real lockdown period. 


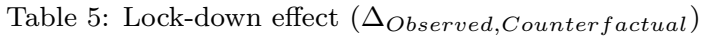
on Badung and Placebo Test

\begin{tabular}{lcc}
\hline \multirow{2}{*}{ Lockdown } & Badung & Placebo \\
\cline { 2 - 3 } & $0.00352 * * *$ & -0.00139 \\
& $(0.00095)$ & $(0.00100)$ \\
Intercept & $0.00347^{* * *}$ & $0.00385 * * *$ \\
& $(0.00044)$ & $(0.00052)$ \\
\cline { 2 - 3 } $\mathrm{N}$ & 2790 & 2196 \\
\hline$* * * \mathrm{p}<0.001 ; * * \mathrm{p}<0.01 ; * \mathrm{p}<0.05$.
\end{tabular}

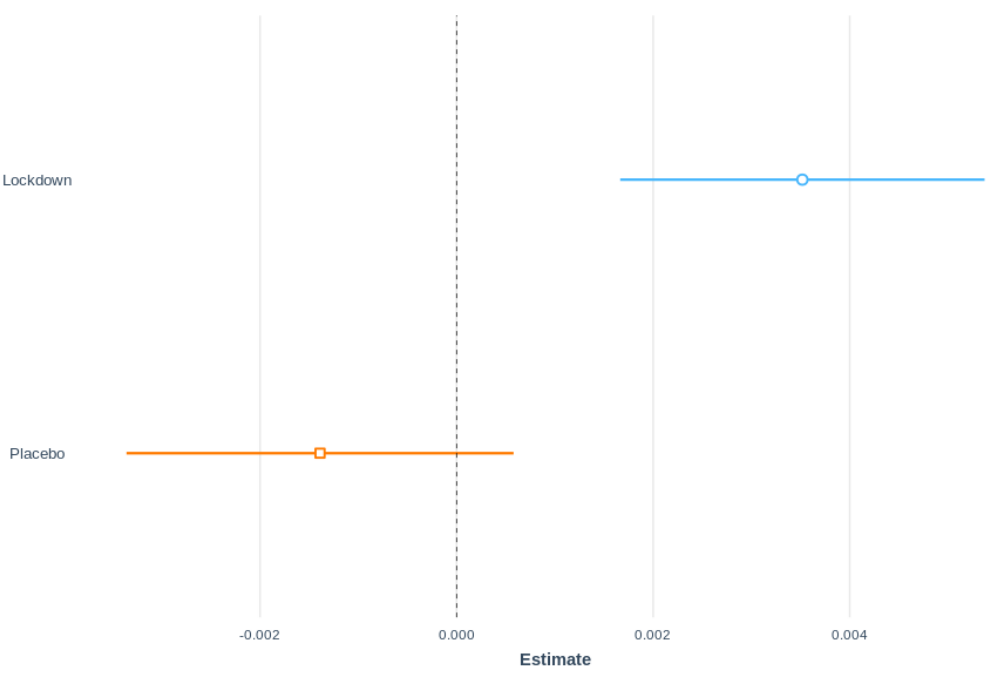

Model

$\begin{array}{ll}-O- & \text { Badung } \\ -\square-\text { Placebo } & \end{array}$

Figure 5: Estimated impact of lockdown and of placebo test on EVI over cropland in Badung (95\% confidence interval).

The results of the robustness check show that the placebo estimation is not statistically significant, while the true lockdown impact has a positive and highly significant impact on the measured EVI index over cropland in Badung. The finding thus allows as to further strengthen the causal interpretation of the analysis. 


\section{Discussion and conclusions}

According to our analysis, the observed increase in the EVI index over Badung, Bali, following the COVID-19 lockdown would not have occurred in the absence of the lockdown. The combination of a counterfactual synthetic EVI based on gradient boosted decision trees with high level of training and testing accuracy and of a placebo test allows confidently linking the two events.

We estimate that the lockdown has on average increased the value of EVI on the whole Badung regency by $1.17 \%$, from the average values that would have been observed had the epidemic not occurred. We also find that in the norther part of the region the EVI has increased by $1.06 \%$ while in the south $1.15 \%$, suggesting a stronger labour market shift towards agriculture in the more touristic south.

But what does a $1 \%$ increase in the EVI index over a short period of time represent? It certainly highlights a significant growth in the canopy structure, such as leaf area and plant physiognomy. Yet, given the large areal extent and heterogeneity in cultivated crops of the region inquired, a direct interpretation in terms of agricultural yield change is not possible. On the other hand, the results have important implications for carbon sequestration, given the strong correlation of EVI with carbon stocks (Situmorang et al. 2016; Dai et al., 2020). As an additional remark, in our study we estimate the short run impact of the lockdown (from May to July). Longer run analysis could shade light on more structural changes in agricultural production system.

Overall, while our approach enables estimating the effect of the lockdown on EVI and linking it with a labour force shift, it does not uncover the increase in the vegetation index's underlying mechanism. In terms of plant phenology, several concurrent reasons could explain this variation such as a decrease in bare soil; an increase in plants health due to greater plant care and a decline in pollution levels or a reduction in the amount of harvested crops due to reduced food demand.

The key limitations of our analysis and its findings consist of the potential uncertainty and error in remotely sensed observations and the scale of analysis in relation to data granularity.

Overall our analysis contributes to the rapidly growing stream of literature linking remotely sensed data, machine learning modelling, and econometric causal inference. 
This is particularly relevant to evaluate policy impacts in near-real-time - when field or conventional data collection has not yet occurred - or in developing regions.

\section{Code and data availability}

The R and Google Earth Engine JavaScript code to replicate the analysis and the figures are publicly hosted at https://github.com/athammad/baliLockDown. The repository includes references to retrieve the input data.

\section{CRediT authorship contribution statement}

Ahmed T. Hammad: Conceptualization, Methodology, Formal analysis, Software, Visualization, Writing - original draft, Writing - review \& editing. Giacomo Falchetta: Conceptualization, Methodology, Data curation, Writing - original draft, Writing - review \& editing. I. B. M. Wirawan: Visualization, Writing - original draft, Writing - review $\&$ editing.

\section{Conflict of interest}

Declaration of interest: none.

\section{Funding}

This research did not receive any specific grant from funding agencies in the public, commercial, or not-for-profit sectors.

\section{References}

Antara, M., Sumarniasih, M.S., 2017. Role of tourism in economy of bali and indonesia. Journal of Tourism and Hospitality Management 5, 34-44.

Ataguba, J.E., 2020. Covid-19 pandemic, a war to be won: understanding its economic implications for africa.

Bartik, A.W., Cullen, Z.B., Glaeser, E.L., Luca, M., Stanton, C.T., 2020. What jobs are being done at home during the COVID-19 crisis? Evidence from firm-level surveys. Technical Report. National Bureau of Economic Research. 
BPS, 2018. URL: https://bali.bps.go.id/publication/2019/11/26/974977b46692e43f ced30919/ statistik-hortikultura-provinsi-bali-2018.html.

BPS, 2020. URL: https://badungkab.bps.go.id/pressrelease/2020/04/02/223/ perkembangan-pariwisata-provinsi-bali-februari-2020.html.

Burke, M., Lobell, D.B., 2017. Satellite-based assessment of yield variation and its determinants in smallholder african systems. Proceedings of the National Academy of Sciences 114, 2189-2194.

Cai, Y., Guan, K., Lobell, D., Potgieter, A.B., Wang, S., Peng, J., Xu, T., Asseng, S., Zhang, Y., You, L., et al., 2019. Integrating satellite and climate data to predict wheat yield in australia using machine learning approaches. Agricultural and forest meteorology 274, 144-159.

Chen, J., Jönsson, P., Tamura, M., Gu, Z., Matsushita, B., Eklundh, L., 2004. A simple method for reconstructing a high-quality ndvi time-series data set based on the savitzky-golay filter. Remote sensing of Environment 91, 332-344.

Chen, T., He, T., Benesty, M., Khotilovich, V., Tang, Y., 2015. Xgboost: extreme gradient boosting. R package version $0.4-2,1-4$.

Cucchi, M., Weedon, G.P., Amici, A., Bellouin, N., Lange, S., Müller Schmied, H., Hersbach, H., Buontempo, C., 2020. Wfde5: bias-adjusted era5 reanalysis data for impact studies. Earth System Science Data 12, 2097-2120.

Dai, X., Yang, G., Liu, D., Wan, R., 2020. Vegetation carbon sequestration mapping in herbaceous wetlands by using a modis evi time-series data set: A case in poyang lake wetland, china. Remote Sensing 12,3000

Danquah, M., Schotte, S., Sen, K., 2020. Covid-19 and employment: Insights from the sub-saharan african experience. The Indian Journal of Labour Economics 63, 23-30.

Dowle, M., Srinivasan, A., Gorecki, J., Chirico, M., Stetsenko, P., Short, T., Lianoglou, S., Antonyan, E., Bonsch, M., Parsonage, H., et al., 2019. Package 'data. table'. Extension of 'data. frame .

Duveiller, G., Baret, F., Defourny, P., 2012. Remotely sensed green area index for winter wheat crop monitoring: 10-year assessment at regional scale over a fragmented landscape. Agricultural and forest meteorology 166, 156-168.

Figueiredo, G.K.D.A., Brunsell, N.A., Higa, B.H., Rocha, J.V., Lamparelli, R.A.C., 2016. Correlation maps to assess soybean yield from evi data in paraná state, brazil. Scientia Agricola 73, 462-470.

Friedman, J.H., 2001. Greedy function approximation: a gradient boosting machine. Annals of statistics 1189-1232.

Funk, C., Peterson, P., Landsfeld, M., Pedreros, D., Verdin, J., Shukla, S., Husak, G., Rowland, J., Harrison, L., Hoell, A., et al., 2015. The climate hazards infrared precipitation with stations-a new environmental record for monitoring extremes. Scientific data 2, 1-21.

Gorelick, N., Hancher, M., Dixon, M., Ilyushchenko, S., Thau, D., Moore, R., 2017. Google earth engine: Planetary-scale geospatial analysis for everyone. Remote sensing of Environment 202, 18-27.

Granella, F., Reis, L.A., Bosetti, V., Tavoni, M., 2020. Covid-19 lockdown only partially alleviates health impacts of air pollution in northern italy. Environmental Research Letters .

Huete, A., Didan, K., Miura, T., Rodriguez, E.P., Gao, X., Ferreira, L.G., 2002. Overview of the radio- 
metric and biophysical performance of the modis vegetation indices. Remote sensing of environment 83, 195-213.

Jain, M., Singh, B., Srivastava, A., Malik, R.K., McDonald, A., Lobell, D.B., 2017. Using satellite data to identify the causes of and potential solutions for yield gaps in india's wheat belt. Environmental Research Letters 12, 094011.

Jia, X., Khandelwal, A., Mulla, D.J., Pardey, P.G., Kumar, V., 2019. Bringing automated, remotesensed, machine learning methods to monitoring crop landscapes at scale. Agricultural Economics 50, $41-50$.

Kesehatan, I., 2020. URL: https://www.diskes.baliprov.go.id/portfolio/ perkembangan-penyebaran-virus-corona.

Kubitza, C., Krishna, V.V., Schulthess, U., Jain, M., 2020. Estimating adoption and impacts of agricultural management practices in developing countries using satellite data. a scoping review. Agronomy for Sustainable Development 40, 1-21.

Kuhn, M., et al., 2008. Building predictive models in $\mathrm{r}$ using the caret package. Journal of statistical software $28,1-26$.

Laula, N., Paddock, R.C., 2020. With tourists gone, bali workers return to farms and fishing. The New York Times URL: https://www.nytimes.com/2020/07/20/world/asia/bali-tourism-coronavirus . html.

Lobell, D.B., Azzari, G., Marshall, B., Gourlay, S., Jin, Z., Kilic, T., Murray, S., 2018. Eyes in the sky, boots on the ground .

Mayer, M., 2019. missranger: Fast imputation of missing values URL: https://CRAN.R-project.org/ package=missRanger. $\mathrm{r}$ package version 2.1.0.

Minister of Law and Human Rights, 2020. URL: https://www.imigrasi.go.id/uploads/ 07-10-24-PERMENKUMHAM_NOMOR_11_TAHUN_2020_TENTANG_PELARANGAN_SEMENTARA_ORANG_ASING_ MASUK_WILAYAH_NEGARA_REPUBLIK_INDONESIA.pdf.

Morcillo-Pallarés, P., Rivera-Caicedo, J.P., Belda, S., De Grave, C., Burriel, H., Moreno, J., Verrelst, J., 2019. Quantifying the robustness of vegetation indices through global sensitivity analysis of homogeneous and forest leaf-canopy radiative transfer models. Remote Sensing 11, 2418.

Running, S., Mu, Q., Zhao, M., 2017. Mod16a2 modis/terra net evapotranspiration 8-day 14 global 500m sin grid v006. NASA EOSDIS Land Processes DAAC 6.

Saha, S., Moorthi, S., Wu, X., Wang, J., Nadiga, S., Tripp, P., Behringer, D., Hou, Y., Chuang, H.y., Iredell, M., et al., 2011. Ncep climate forecast system version 2 (cfsv2) 6-hourly products. Research Data Archive at the National Center for Atmospheric Research, Computational and Information Systems Laboratory .

Situmorang, J.P., Sugianto, S., Darusman, D., 2016. Estimation of carbon stock stands using evi and ndvi vegetation index in production forest of lembah seulawah sub-district, aceh indonesia. Aceh International Journal of Science and Technology 5, 126-139.

Sjöström, M., Ardö, J., Arneth, A., Boulain, N., Cappelaere, B., Eklundh, L., De Grandcourt, A., Kutsch, W.L., Merbold, L., Nouvellon, Y., et al., 2011. Exploring the potential of modis evi for 
modeling gross primary production across african ecosystems. Remote sensing of environment 115, 1081-1089.

Son, N., Chen, C., Chen, C., Minh, V., Trung, N., 2014. A comparative analysis of multitemporal modis evi and ndvi data for large-scale rice yield estimation. Agricultural and forest meteorology 197, 52-64.

Stekhoven, D.J., Buhlmann, P., 2011. Missforest-non-parametric missing value imputation for mixedtype data. Bioinformatics 28, 112-118. doi:10.1093/bioinformatics/btr597.

Teluguntla, P., Thenkabail, P.S., Xiong, J., Gumma, M.K., Giri, C., Milesi, C., Ozdogan, M., Congalton R., Tilton, J., Sankey, T.T., et al., 2015. Global cropland area database (gcad) derived from remote sensing in support of food security in the twenty-first century: current achievements and future possibilities .

Udayana, U., 2020. URL: https://udayananetworking.unud.ac.id/professor/scientific/2476/ the-paralysis-of-tourism-and-the-rise-of-agriculture-in-bali-indonesia-429.

Viña, A., Gitelson, A.A., Nguy-Robertson, A.L., Peng, Y., 2011. Comparison of different vegetation indices for the remote assessment of green leaf area index of crops. Remote Sensing of Environment $115,3468-3478$.

Wan, Z., Hook, S., Hulley, G., 2015. Mod11a1 modis/terra land surface temperature/emissivity daily 13 global $1 \mathrm{~km}$ sin grid v006 [data set]. nasa eosdis lp daac.

Welle, D., 2020. Bali tourist workers return to their roots during pandemic — dw - 01.10.2020. URL: https://www.dw.com/en/bali-tourist-workers-return-to-their-roots-during-pandemic/ av-55121482.

Wolanin, A., Camps-Valls, G., Gómez-Chova, L., Mateo-García, G., van der Tol, C., Zhang, Y., Guanter, L., 2019. Estimating crop primary productivity with sentinel-2 and landsat 8 using machine learning methods trained with radiative transfer simulations. Remote Sensing of Environment 225, $441-457$.

Wright, M.N., Ziegler, A., 2015. ranger: A fast implementation of random forests for high dimensional data in $\mathrm{c}++$ and r. arXiv preprint arXiv:1508.04409 .

WTTC, 2020. Crisis preparedness, management recovery. URL: https://wttc.org/Initiatives/ Crisis-Preparedness-Management-Recovery.

Yamamoto, Y., Shigetomi, Y., Ishimura, Y., Hattori, M., 2019. Forest change and agricultural productivity: Evidence from indonesia. World Development 114, 196-207. 


\section{Appendix A. Supplementary tables and figures}

Table Appendix A.1: Population of the districts of Badung

\begin{tabular}{llll}
\hline \multirow{2}{*}{ District } & \multicolumn{3}{l}{ Population (Thousand inhabitants) } \\
\cline { 3 - 5 } & 2020 & 2019 & 2018 \\
Kuta Selatan & 176,95 & 170,84 & 152,60 \\
Kuta & 112,38 & 110,10 & 102,77 \\
Kuta Utara & 142,03 & 138,42 & 127,40 \\
Mengwi & 133,61 & 132,78 & 130,04 \\
Abiansemal & 92,63 & 92,34 & 91,28 \\
Petang & 25,60 & 25,72 & 25,91 \\
Total & 683,20 & 670,20 & 630,00
\end{tabular}

Source: Central Bureau of Statistics Indonesia Badung Regency (2020)

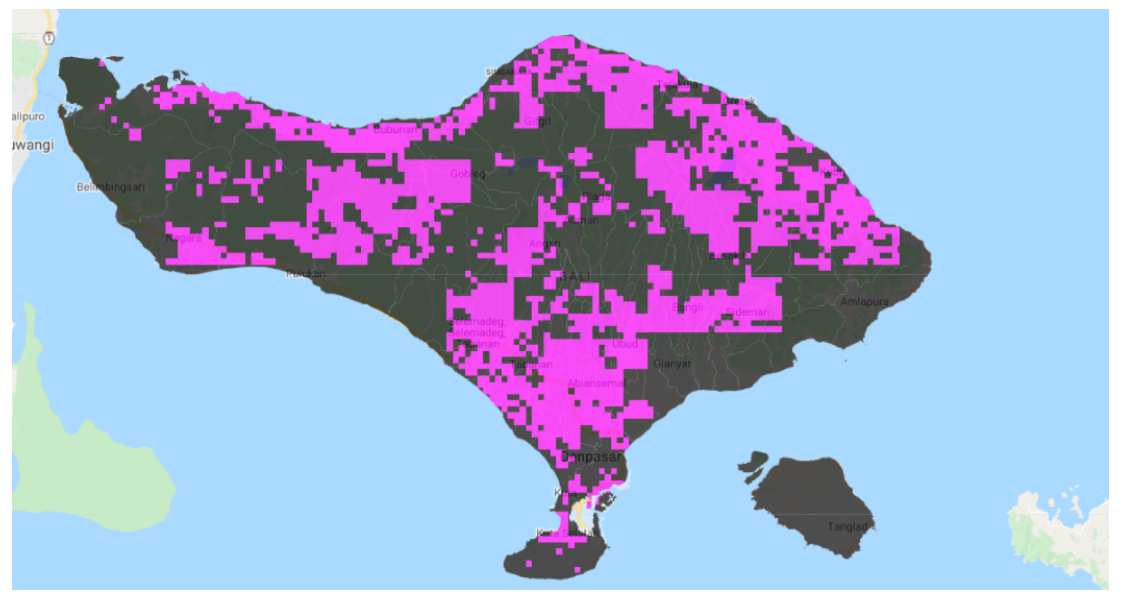

Figure Appendix A.1: Pixels containing cropland over Bali are highlighted in purple. 